\title{
Artículos
}

\section{La defensoría de la comunidad universitaria en el contexto de las defensorías parlamentarias}

University ombuds person in the context of the parliamentary ombuds

\author{
Paulino César Pardo Prieto \\ Defensor de la Comunidad Universitaria. Universidad de León \\ pcparp@unileon.es
}

\begin{abstract}
Resumen
En España, la Ley Orgánica 3/1981 instituyó el Defensor del Pueblo. En los años posteriores, el desarrollo de las autonomías ha dado lugar al surgimiento de figuras paralelas sujetas en su actividad al respectivo ámbito territorial. En el ámbito europeo, también los tratados constitutivos contemplaron esta figura. Por su parte, la figura del Defensor Universitario se hace operativa por primera vez en la Universidad de León, en 1987, a la luz de lo previsto en su Estatuto. La Ley Orgánica 6/2001, de Universidades, propuso para la institución las finalidades de "velar por el respeto a los derechos y las libertades de los profesores, estudiantes y personal de administración y servicios" y actuar en orden a la "mejora de la calidad universitaria en todos sus ámbitos"; estableciendo, a su vez, que "no estará sometida a mandato imperativo de ninguna instancia universitaria". A partir de esos datos, de su tradición previa y, teniendo siempre a la vista la regulación del Defensor del Pueblo nacional, si bien cada Defensoría ha elaborado su modelo y a pesar de la diversidad, dominan los rasgos comunes.
\end{abstract}

Palabras clave: Defensoría universitaria; Defensor del Pueblo español; Procurador del Común; Defensor del Pueblo europeo;

\begin{abstract}
:
In Spain, LO 3/1981 instituted the Ombudsman. In the following years, the development of the autonomies has given rise to the appearance of similar bodies subject in its territories. At the European level, the constitutive treaties also contemplated this charge. The institution of the Spanish University Ombuds becomes operational for the first time at the University of León in 1987 in accordance with its own Statutes. The Spanish Basic Law on Universities, number 6/2001, added new purposes for the institution of University Ombudsman, including to watch over the rights and freedoms of the academic staff, students, and administrative and support staff, and working towards improvements in all aspects of the quality of universities. The Law also established that the functions of the Ombuds person should not be subject to the orders or under the control of any part of a university's organization. On this basis, combined with their individual precedents, the various Ombudsman's Offices have developed their own institutional models. Despite this diversity, certain common features predominate.
\end{abstract}


Keywords: University Ombuds person; European and Spanish Ombudsman's Offices: Ombudsman of Castile and Leon.

Sumario. 1-Estatuto del Defensor del Pueblo español, de los Defensores autonómicos y del Defensor del Pueblo europeo. 2-La Comunidad Universitaria a la que se dirige la Defensoría. 3-Una encuesta para conocer la realidad de las Defensorías de la Comunidad Universitaria españolas. 4-Principales resultados. 5-Algunas conclusiones.

\section{Estatuto del Defensor del Pueblo español, de los defensores autonómicos y del Defen- sor del Pueblo europeo}

La naturaleza y funciones del ombuds vinculado a los poderes públicos se presenta con unos caracteres muy similares. A continuación, me referiré a ellos, haciendo un recorrido por el autonómico Procurador del Común, el nacional Defensor del Pueblo y, en el ámbito supraestatal, el Defensor europeo. Comprobaremos hasta qué punto pueden identificarse aquellos caracteres dentro de la institución de la defensoría de la comunidad universitaria.

La defensoría es una institución vinculada a las cámaras parlamentarias ${ }^{1}$ que, en su ámbito territorial, desempeña tareas de promoción, garantía y protección de los derechos ciudadanos frente a las administraciones y organismos dependientes, funciones generales dentro de las que suelen identificarse explícitamente ciertas labores especializadas².

Por el tipo de competencias que tiene atribuidas, suele requerirse de la persona titular que cumpla unos requisitos de los que se deduzca su autoridad, independencia, eficacia, integridad o experiencia, algo en lo que redunda la necesidad de mayorías cualificadas para su elección o la determinación de términos para el ejercicio del cargo diferenciados de aquellos previstos en las instituciones cuya actividad supervisan³. Incurrir en faltas que determinen la pérdida de

\footnotetext{
${ }^{1}$ Es un "alto comisionado" de las Cortes Generales o de la correlativa asamblea autonómica; véanse, respectivamente, el art. 1 de la Ley Orgánica 3/1981, de 6 de abril, del Defensor del Pueblo (BOE de 7 de mayo) y el art. 1 de la Ley 2/1994, de 9 de marzo, del Procurador del Común de Castilla y León (BOE de 29 de marzo). Es la "persona elegida por el Parlamento Europeo", art. 228 Versión consolidada del Tratado de la Unión Europea y del Tratado de Funcionamiento de la Unión Europea (2012/C 326/01) y art. 1 del Estatuto del Defensor del Pueblo Europeo, aprobado por Decisión del Parlamento de 9 de marzo de 1994 (DO L 113 de 4.5.1994), modificada por las Decisiones de 14 de marzo de 2002 (DO L 92 de 9.4.2002) y de 18 de junio de 2008 (DO L 189 de 17.7.2008).

${ }^{2} \mathrm{Al}$ Defensor del Pueblo, le corresponde "la defensa de los derechos comprendidos en el Título I de la Constitución, a cuyo efecto podrá supervisar la actividad de la Administración" pero también, por ejemplo, las funciones del Mecanismo Nacional de Prevención de la Tortura de conformidad con la Constitución, la presente Ley y el Protocolo facultativo de la Convención contra la tortura u otros tratos o penas crueles, inhumanos o degradantes (art. 1 y DF Única de la LO 3/1981 así como los arts. 19 a 22 del Reglamento del Consejo Asesor del Mecanismo). El Procurador, además de aquella tutela general, "supervisa la actuación de la Administración regional, entes, organismos y de las autoridades y del personal", por ejemplo, a través del control de la política de transparencia (art. 1 de la Ley 2/1994). La institución europea, podrá "cooperar con instituciones y órganos de los Estados miembros encargados del fomento de la protección de los derechos fundamentales" y "contribuirá a descubrir los casos de mala administración en la acción de las instituciones y órganos comunitarios, con exclusión del Tribunal de Justicia y del Tribunal de Primera Instancia en el ejercicio de sus funciones jurisdiccionales, y a formular recomendaciones para remediarlos" (art. 2 del Estatuto); en el ejercicio de su actividad promotora, por ejemplo, ha dirigido a la Comisión una Recomendación sobre "El uso de las lenguas oficiales de la UE en la comunicación con el público - Recomendaciones prácticas para la Administración de la UE" (29 de junio de 2020).

3 El Defensor del Pueblo español y el Procurador del Común se eligen por mayoría de 3/5 entre ciudadanos que estén en el pleno ejercicio de sus derechos (art. 3 LO 3/1981; art. 5 Ley 2/1994); la Defensoría europea, podrá recaer en "una personalidad que tenga la ciudadanía de la Unión, se encuentre en pleno disfrute de sus derechos civiles y políticos, ofrezca plenas garantías de independencia y reúna las condiciones requeridas en su país para el ejercicio de las más al-
} 
aquellos requisitos, la negligencia en el cumplimiento de las obligaciones y deberes del cargo o la incompatibilidad apreciada por las cámaras, determinan el inicio de procedimientos de cese que, eso sí, van acompañados de procedimientos que tratan de garantizar al máximo la posición de la persona titular y el buen funcionamiento de la institución.

En el desarrollo de sus funciones, dispone de plena autonomía e independencia, no está sometido a mandato imperativo ni recibe instrucciones de ninguna autoridad; investiga y resuelve los expedientes conforme a su propio criterio y la persona titular es inviolable en el ejercicio de su cargos. La garantía formal de su independencia conlleva, al mismo tiempo, la incompatibilidad de su desempeño con cualquier mandato representativo; cargo político o actividad de propaganda política; la permanencia en activo dentro de la Administración pública; con la afiliación o el desempeño laboral o de funciones directivas en partidos políticos, sindicatos, asociaciones; el ejercicio de las carreras judicial y fiscal o, en general, con cualquier actividad profesional, liberal, mercantil o laboral ${ }^{6}$.

Para realizar con eficacia su misión, administraciones y poderes públicos están obligados a auxiliar, con carácter preferente y urgente, a las defensorías; las limitaciones relativas al acceso a expedientes o documentos no podrán ser sino aquellas expresamente determinadas por la Ley. El incumplimiento de esa obligación por personas o entidades puede conllevar distintos tipos de sanciones laborales, administrativas o penales o, en su caso, la inmediata intervención de los parlamentos o el propio poder judicial, que facilitarán el rápido y más amplio cumplimiento de lo requerido por el defensor, sin perjuicio de un posterior reproche que, en lo que respecta a la institución, dará lugar al señalamiento explícito en la memoria anual o, incluso, a un expediente separado? ${ }^{7}$. Lo que no podrán hacer las defensorías es intervenir en cuestiones que estén pendientes de resolución judicial o hayan sido objeto de la misma8.

La actuación de las defensorías se produce de oficio o a instancia de parte, proponiendo a los organismos, autoridades y personal al servicio de las administraciones afectadas cuantas advertencias, recomendaciones y recordatorios relativos a sus deberes legales considere oportuno; sugiriendo la modificación de los criterios utilizados para la producción de actos y resoluciones o, en su caso, señalando pautas al órgano legislativo competente o a la Administración para la modificación de normas o del modo de

tas funciones jurisdiccionales o posea experiencia y competencia notorias para el ejercicio de las funciones de Defensor del Pueblo" (art. 6 Estatuto).

${ }^{4}$ Así, el Defensor del Pueblo, cesará por "...actuar con notoria negligencia en el cumplimiento de las obligaciones y deberes del cargo" y se decidirá, por mayoría de las tres quintas partes de los componentes de cada Cámara" (art. 5.1,4 y 5.2 LO 3/1981) la misma circunstancia y mayoría prevista en la Ley 2/1994, que también contempla "la inhabilitación para el ejercicio de los derechos políticos declarada por sentencia firme" y la "incompatibilidad sobrevenida apreciada por las Cortes de Castilla y León". En el ámbito europeo, a petición del Parlamento, el Tribunal de Justicia podrá destituir al Defensor "si éste dejare de cumplir las condiciones necesarias para el ejercicio de sus funciones o hubiere cometido una falta grave" (art. 8 Estatuto).

${ }^{5}$ Véase el art. 6 LO 3/1981 y el art. 1 Ley 2/1994. La persona titular de la Defensoría europea: "ejercerá sus funciones con total independencia y atendiendo al interés general de las Comunidades y de los ciudadanos de la Unión. En el ejercicio de sus funciones, no solicitará ni admitirá instrucciones de ningún Gobierno ni de ningún organismo"; además: "Se aplicarán al Defensor del Pueblo y a los funcionarios y agentes de su secretaría los artículos 12 a 15 y 18 del Protocolo sobre los privilegios e inmunidades de las Comunidades Europeas" (arts. 9.1 y 10.2 Estatuto).

${ }^{6}$ Véase el art. 7 LO 3/1981, en similar sentido, art. 8 Ley 2/1994 y art. 10 Estatuto.

${ }^{7}$ Véanse los arts. 19 y 24 LO 3/1981; 3, 16, 18 Ley 2/1994 У 3 y 4 Estatuto.

${ }^{8}$ Art. 17.2 LO 3/1981; art. 12.2 Ley 2/1994; art. 2.7 Estatuto. 
ejecutarlas o interpretarlas, si considera que conducen a un resultado injusto; contra su decisión no cabe recurso, pudiendo, en ocasiones, señalar un plazo máximo para el cumplimiento 9 . Desde luego, sin renunciar a conciliar la solución de los procedimientos cuando ello sea posible ${ }^{10}$.

Elemento común a todas las defensorías es la rendición ante el órgano legislativo de un informe ordinario anual acerca de sus actuaciones en el que presenta sistemáticamente aspectos cuantitativos y cualitativos de su labor (número y características de las quejas recibidas, de los procedimientos seguidos de oficio; de sus resultados, del sentido de sus intervenciones y recomendaciones, etc.). Dichos informes suelen ser complementados por otros extraordinarios, relativos a cuestiones que merecen a juicio del órgano un tratamiento más pormenorizado" ${ }^{1}$.

Común es también la previsión de distintas fórmulas de cooperación con instituciones análogas ${ }^{12}$. Se trata de una eventualidad que debe merecer la consideración de las defensorías de la comunidad universitaria, tanto en los planos nacional e internacional (cuando se trata de entidades o federaciones de entidades estatales o supranacionales) como en los ámbitos autonómicos.

En el caso de Castilla y León, las universidades públicas han ido habilitando convenios con el Procurador del Común que están dando interesantes frutos en los últimos años.

El convenio responde a unas cláusulas tipo pactadas por las personas titulares de cada una de las instituciones y rubricadas por las representaciones de las partes, en nuestro caso, el Procurador del Común y cada uno de los rectores de las universidades interesadas.

Se prevé como objeto de la colaboración fortalecer el desarrollo de los derechos y libertades de los miembros de la Comunidad Universitaria, para ello se seguirán tres mecanismos:

1. La Defensoría podrá instar la actuación del Procurador del Común en aquellos temas cuyas especiales circunstancias entienda aconsejan la intervención ${ }^{13}$.

2. El Procurador del Común, en la tramitación de quejas referidas a la Universidad, podrá recabar la colaboración del Defensor de la Comunidad cuando estime que puede contribuir a la mejora, agilidad y eficacia de sus gestiones ${ }^{14}$.

3. El Defensor de la Comunidad Universitaria remitirá periódicamente al Procurador del Común una relación nominal de las quejas que hayan tenido entrada en su oficina en dicho periodo, a fin de detectar posibles duplicidades por haberse dirigido simultáneamente el ciudadano a ambas instituciones ${ }^{15}$.

\footnotetext{
${ }_{9}^{9}$ Véanse los arts. 12, 19 y 20 Ley 2/1994; 5 y 6 Estatuto; 17, 28 y 30 LO 3/1981; en este sentido, el Defensor del Pueblo español está también autorizado a interponer recurso de amparo y de inconstitucionalidad ante el TC, art. 29.

${ }^{10}$ Art. 9 LO 3/1981; art. 20 Ley 2/1994; art. 5 Estatuto.

${ }^{11}$ Art. 32 LO 3/1981; arts. 2 y 31 Ley 2/1994; art. 3, apartados 7 y 8 Estatuto.

${ }^{12}$ Art. 12 LO 3/1981; art. 4 Ley 2/1994; art. 5.1, primer inciso, Estatuto.

${ }^{13}$ Cláusulas 1 a 3 Convenio ULe.

${ }^{14}$ Cláusula 5 Convenio ULe.

15 Cláusula 6 Convenio ULe.
} 


\section{La comunidad universitaria a la que se dirige la defensoría}

El Sistema Universitario Español lo constituían en el curso 2018-2019 un total de 83 universidades, 50 públicas y 33 privadas ${ }^{16}$. Del total de casi 1.600 .000 estudiantes universitarios, 1.300.000 lo eran de Grado; 210.000 de Máster y 90.000 de Doctorado. Llamativamente, aunque las mujeres constituyen el 55\% del estudiantado de Grado y Máster, el porcentaje desciende al 50\% en el Doctorado y, sobre todo, son importantes las diferencias por sexos en las ramas de Ingeniería y Arquitectura: Hasta un 75,2\% de los matriculados y un $71,5 \%$ de los egresados fueron hombres. Por el contrario, en la rama de Ciencias de la Salud, eran poco más del $29 \%$ el porcentaje de los hombres matriculados y egresados ${ }^{17}$.

El 36\% de los estudiantes de nuevo ingreso en el curso 2014-2015 finalizó sus estudios en el tiempo teórico y el 49\% de los estudiantes de nuevo ingreso en el estudio del curso 20132014 finalizó con un año de retraso como máximo. En torno al 15\% abandonó sus estudios, si bien, ese abandono ofrece cifras porcentuales muy distintas en algunas titulaciones; sensiblemente superiores para ingenierías y arquitectura, inferiores para Ciencias de la Salud ${ }^{18}$.

El Personal Investigador contratado lo constituían 26.000 trabajadores, el Docente e Investigador, ascendía a 123.000; el de Administración y Servicios, a 62.000 ${ }^{19}$. Dentro del PDI público, 104.000 trabajadores, el 41\% son funcionarios y, de ellos, 10.800, Catedráticos de Universidad; 27.500, Titulares de Universidad, y 3.700 Titulares de Escuela Universitaria. Entre los contratados, la mitad son asociados y el $20 \%$ del total, Ayudantes y Contratados Doctores. Son cifras que evidencian una notable precariedad y deficiente retribución. Entre los 30 y los 60 años, se da una paridad de hombres y mujeres, salvo en ámbitos de conocimiento como las ingenierías, agricultura, ganadería o servicios, donde la masculinización alcanza hasta el $80 \%$ en algún caso ${ }^{20}$.

El porcentaje de gasto de personal (Capítulo I) sobre gasto total es del 65\%; el porcentaje de gasto en bienes y servicios (Capítulo II), el 14\%. Del lado de la financiación, el porcentaje que proporcionaron las tasas y precios públicos sobre los ingresos totales fue del 17\%, siendo el grado de dependencia de la financiación de las Comunidades Autónomas del $65 \%{ }^{21}$.

\section{Una encuesta para conocer la realidad de las Defensorías de la Comunidad Universitaria española}

Durante el curso 2018/2019, la Defensoría de la Comunidad Universitaria de la Universidad de León envió una propuesta de Reglamento al Rectorado de la Universidad solicitando fuera sometido a aprobación del Claustro, con ese motivo, quisimos conocer el estado actual de la institución, integrando en nuestro nuevo reglamento aquellos desarrollos más funcionales y avanzados contemplados por las defensorías españolas.

\footnotetext{
${ }^{16}$ MINISTERIO DE UNIVERSIDADES. Datos y cifras del sistema universitario español. Publicación 2019-2020, edit. Secretaría General Técnica del Ministerio de Ciencia e Innovación, Madrid, 2020, pp. 8-9.

${ }^{17}$ Ibíd., p. 25.

${ }^{18}$ Ibíd., pp. 41 y ss.

${ }^{19}$ Ibíd., pp. 8 y 107 y ss.

${ }^{20}$ Ibíd., pp. 110 y ss.

${ }^{21}$ Ibíd., p. 105.
} 
La Ley Orgánica 6/2001, de Universidades, al regular la figura del Defensor Universitario, únicamente prevé que:

Para velar por el respeto a los derechos y las libertades de los profesores, estudiantes $y$ personal de administración y servicios, ante las actuaciones de los diferentes órganos y servicios universitarios, las Universidades establecerán en su estructura organizativa la figura del Defensor Universitario. Sus actuaciones, siempre dirigidas hacia la mejora de la calidad universitaria en todos sus ámbitos, no estarán sometidas a mandato imperativo de ninguna instancia universitaria y vendrán regidas por los principios de independencia y autonomía.

Hay, pues, unos altos fines previstos para la institución ("velar por el respeto a los derechos y las libertades de los profesores, estudiantes y personal de administración y servicios" / "mejora de la calidad universitaria en todos sus ámbitos") y hay una regla de oro para su funcionamiento ("no estará sometida a mandato imperativo de ninguna instancia universitaria"). Sobre esos mimbres, cada una de las universidades españolas ha construido su propio modelo de Defensoría aunque, como veremos, en todas ellas imperan, como un tronco común de buscada referencia, los caracteres habituales de las defensorías de los poderes públicos y, en particular, del Defensor del Pueblo estatal.

A continuación, se ofrecen los resultados de esta encuesta en la que participaron 48 universidades, dos tercios de las asociadas a la Conferencia Estatal de Defensorías Universitarias. Ilustra, por tanto, muy bien el panorama de la institución en España. Este trabajo solo fue posible, por tanto, gracias a la colaboración de todas ellas ${ }^{22}$.

\section{Principales resultados.}

1. Quiénes son los posibles titulares de la Defensoría de la Comunidad Universitaria: (1) Personalidad no universitaria de prestigio; (2) Profesores, Personal de Administración y Servicios, Estudiantes, Personalidad no universitaria de prestigio; (3) Profesores, Personal de Administración y Servicios, Personalidad no universitaria de prestigio; (4) Profesores, Personal de Administración y Servicios; (5) Profesores; (6) Profesores, Personal de Administración y Servicios, Estudiantes.

2. La Defensoría dispone de un registro propio e independiente para los escritos que le son dirigidos.
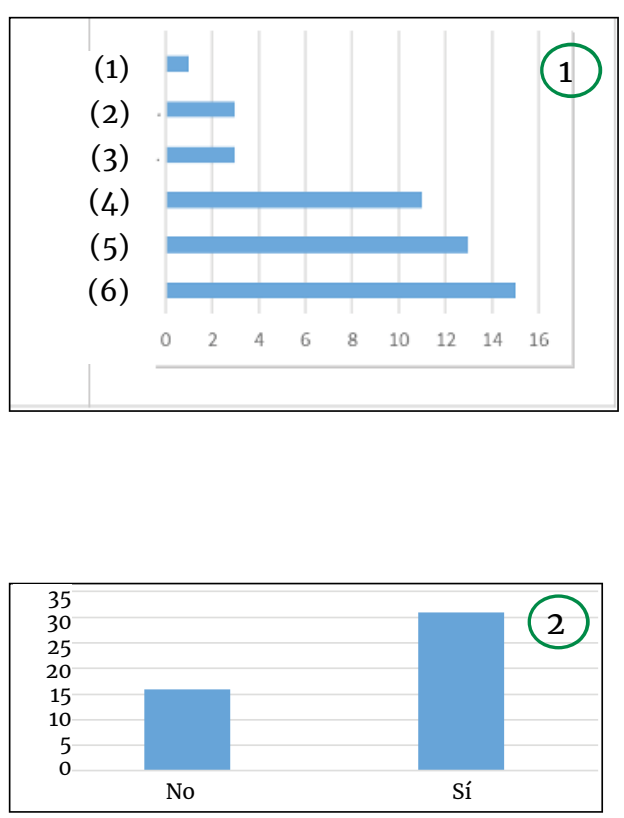

\footnotetext{
${ }^{22} \mathrm{Mi}$ agradecimiento a cada una de las Defensorías de las Universidades participantes y a la CEDU, en especial, por su apoyo y ayuda en la elaboración del muestreo y exposición de los resultados, a su Presidente, el Prof. Antonio García Ruíz, así como al Prof. Emilio Olías Ruíz, de la Universidad Carlos III, y a mi predecesora en la Defensoría de la Comunidad Universitaria de la Universidad de León, Profa. Marta Elena Alonso de la Varga.
} 
3. La persona titular del cargo podrá ser sometida a expediente disciplinario por razón de las opiniones expresadas o por las actuaciones acometidas en el legítimo ejercicio de sus funciones.

4. El tratamiento del cargo, se asimila a efectos protocolarios a...23
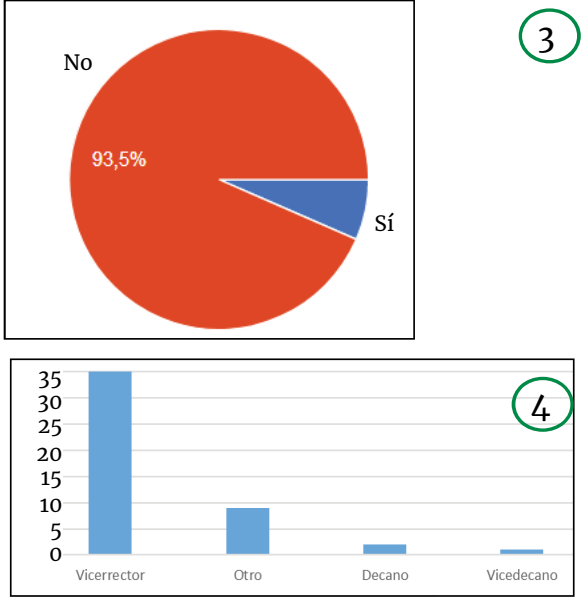

5. El tratamiento del cargo, se asimila a efectos económicos a....

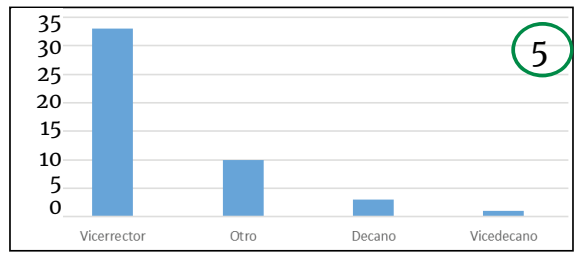

6. El tratamiento, se asimila a efectos de descarga docente a....

7. El presupuesto de la Defensoría viene establecido: (1) Por el Claustro (2) Autónomamente por la propia Defensoría (3) Mediante la participación conjunta de la Defensoría y Rectorado/ Claustro/Consejo Social/Otro (4) Por el Recto-
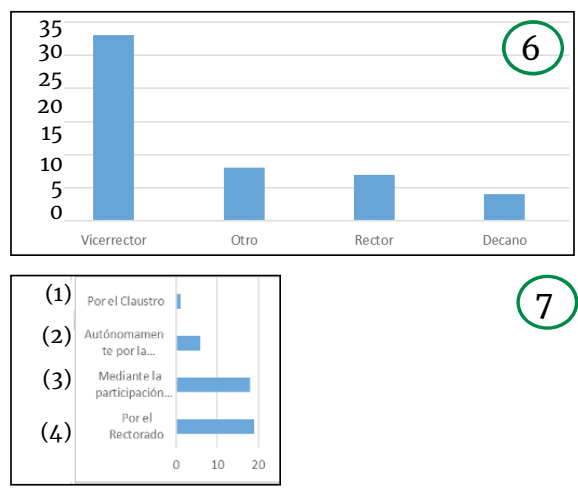
rado.

8. La persona titular de la Defensoría puede asistir a petición propia: (1) A las sesiones de los órganos colegiados de Gobierno (2) A las sesiones de los órganos colegiados de la Universidad (3) A las sesiones de los órganos colegiados de Gobierno y a las sesiones de los órganos colegiados de la Universidad (4) No se ha previsto expresamente tal posibilidad.

9. ¿Las candidaturas a Defensor/a se presentan libremente o ha de cumplirse algún requisito previo por parte de los posibles candidatos? (1) $\mathrm{Si}$, libremente, (2) No, a propuesta del Rector, (3) No, a propuesta de un número de
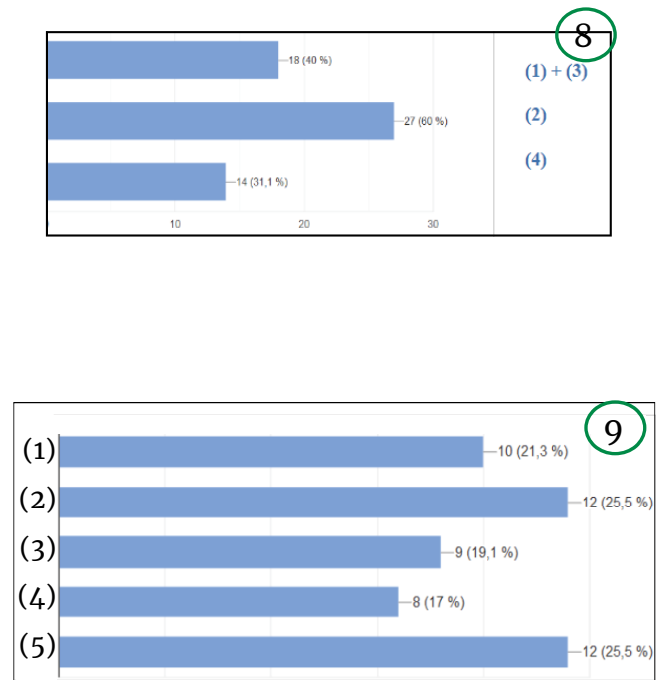

\footnotetext{
${ }^{23}$ En este gráfico y los siguientes, las indicaciones "otro" corresponden a: Deusto, Universitat de València, Granada, Cantabria, Universitat Politecnica de Catalunya, Universidad Internacional de Valencia, Antonio de Nebrija, Alicante y Universidad Pontificia de Salamanca. Llega a ser Rector, en las universidades públicas, o bien figuras específicas de las universidades privadas.
} 
claustrales, (4) No, se requiere un número mínimo de firmas que avalen la candidatura, (5) No, otro requisito.

10. La elección por el Claustro de la persona titular de la Defensoría ${ }^{24}$ ¿Qué tipo de mayoría requiere en primera vuelta? 1) Mayoría simple (2) Mayoría absoluta de los integrantes del claustro (3) Mayoría cualificada superior

11. La elección por el Claustro de la persona titular de la Defensoría ¿Qué tipo de mayoría requiere en segunda vuelta? (1) Mayoría simple (2) Mayoría absoluta de los integrantes del claustro. (3) Mayoría cualificada superior.

12. ¿Está prevista la convocatoria del proceso de elección en un plazo anterior a la expiración del mandato de modo que no se dilate la terminación del mismo?

13. La titularidad de la Defensoría es incompatible con el ejercicio de otros cargos... (1) De gobierno de la Universidad; (2) De gobierno de la Universidad + representación de la Universidad; (3) De gobierno de la Universidad + representación de la Universidad + carácter político fuera de la Universidad + orgánicos en partidos políticos y en sindicatos (4) De gobierno de la Universidad + representación de la Universidad + sindicatos; (5) De gobierno de la Universidad + representación de la Universidad + orgánicos en partidos políticos + sindicatos.

14. Se ha previsto la remoción de la persona titular de la Defensoría por el Claustro.... (1) Por actuar con notoria negligencia o mala fe; (2) Por incumplir las obligaciones y deberes de su cargo; (3) Además por otros motivos.
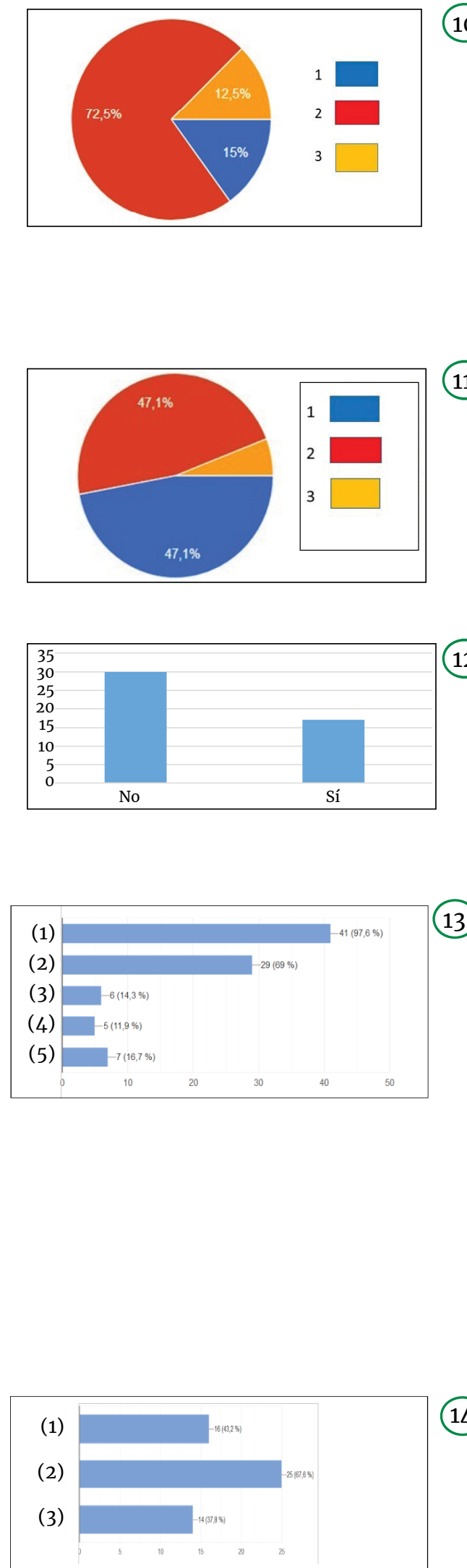

\footnotetext{
${ }^{24}$ Entre las públicas, excepcional es la regulación de la Universidad Politécnica, al prever el sufragio directo por la Comunidad Universitaria.
} 
15. Para que la remoción prospere se requiere en última instancia una votación con: (1) Mayoría simple. (2) Mayoría absoluta de los integrantes del claustro. (3) Mayoría cualificada superior.

16. ¿La Defensoría dispone de uno o más adjuntos...? En la generalidad de las defensorías disponen de adjuntos: Antonio de Nebrija, Granada, Extremadura, Málaga, Universidad Politécnica de Madrid, Sevilla, Oviedo, Universidad Rey Juan Carlos, Universidad Nacional de Educación a Distancia (UNED), Alcalá (UAH), Universidad Autónoma, Zaragoza, Universitat Politècnica de València... Difieren entre sí acerca del carácter, elección, consideración, etc. En algunos casos, hay dos adjuntos y pertenecen a un sector distinto de la persona titular de la Defensoría, así sucede por ejemplo en León, o tres adjuntos pertenecientes a cada uno de los sectores de la comunidad universitaria, como es el caso de Valladolid..

17. La Defensoría presenta su memoria anual al Claustro y la publica seguidamente en medios de difusión fácilmente accesibles para toda la comunidad universitaria.

18. El mandato de la persona titular de la Defensoría tendrá una duración de...

19. ¿El mandato es renovable?25

20. La Defensoría, junto a las tareas habituales expresamente atribuidas por la Ley de Universidades... (1) Colabora en los procedimientos de prevención de acoso; (2) Colabora en los procedimientos de prevención de acoso, Participa en la actividad de la unidad de igualdad; (3) Colabora en los procedimientos de prevención de acoso, Organiza jornadas y cursos; (4) Colabora en los procedimientos de prevención de acoso, Organiza jornadas y cursos / participa en la actividad de igualdad, se reúne con los representantes de la Comunidad Universitaria con cierta periodicidad; (5) Propone textos articulados para su aprobación por los órganos de gobierno de la Universidad.
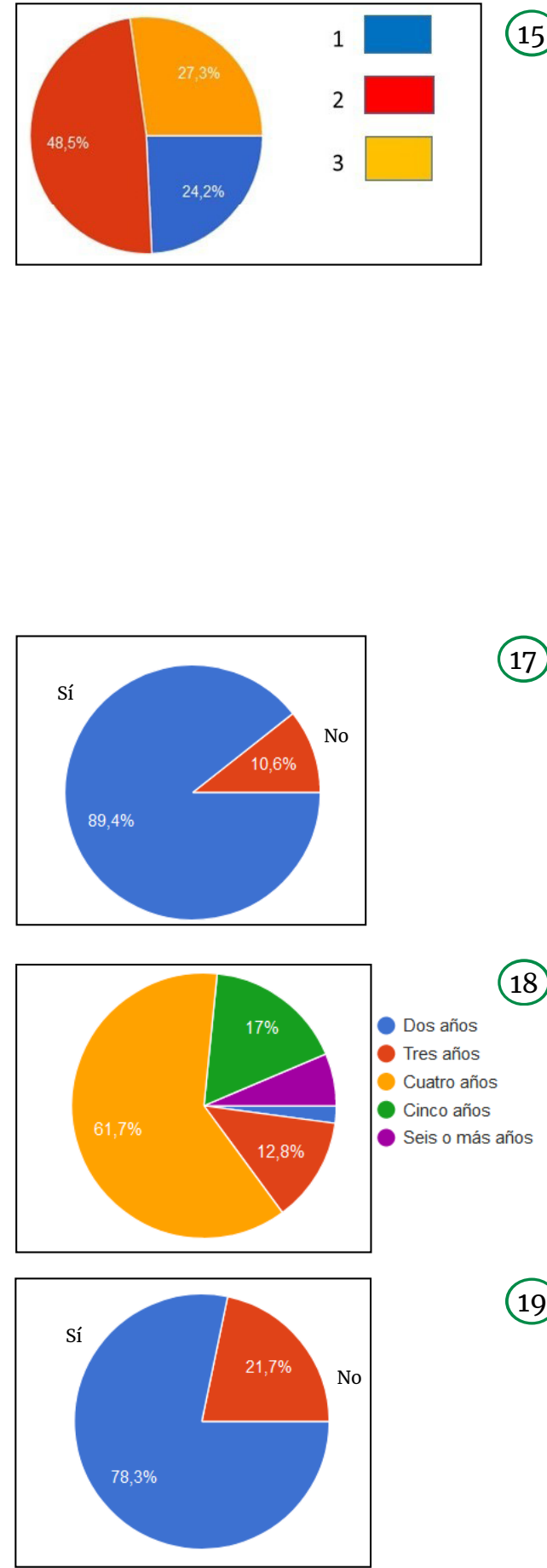

(19)

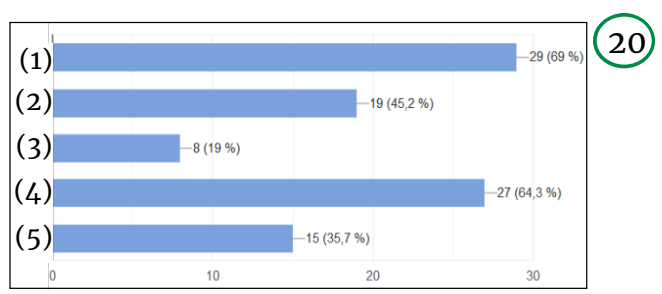

${ }^{25}$ Entre las defensorías que respondieron a la encuesta, no es renovable en dos universidades cuyo mandato es de cuatro años: Universitat de València y Las Palmas de Gran Canaria: Ni en otras siete que prevén un mandato de cinco años: Oberta de Catalunya, Vigo, Alicante, Sevilla, Islas Baleares, Las Palmas de Gran Canaria y Universitat Jaume I de Castelló. 


\section{Algunas conclusiones}

Por una parte, hemos comprobado hasta qué punto las Defensorías de la Comunidad Universitaria españolas se han configurado en paralelo a sus homólogas insertas en los poderes públicos (defensorías del pueblo estatal, europea y autonómicas):

- Asumen tareas de promoción, garantía y protección de los derechos frente ante la actividad administrativa de la Universidad, su personal y sus organismos dependientes.

- Están generalmente comisionadas por los claustros, que se muestran en el papel de cámaras de representación de la comunidad universitaria.

- De la persona titular, se exige autoridad y autonomía. Requieren habitualmente mayorías cualificadas para la elección o cese; se establecen términos para el ejercicio del cargo diferenciados de los previstos para la renovación del claustro o del rectorado; no está sometido a mandato imperativo, investiga y resuelve los expedientes conforme a su propio criterio, la persona titular es inviolable y supuestos de incompatibilidad, más o menos amplios, garantizan formalmente su carácter independiente.

- Actúan de oficio o a instancia de parte, la administración universitaria ha de facilitar su tarea investigadora. No obstante, les es vetado intervenir en cuestiones que estén tramitándose administrativamente o hayan sido objeto de resolución administrativa. Una de sus características más señaladas es la actividad mediadora.

- La presentación y defensa ante el claustro de la memoria anual, procediendo luego a su publicación, es una de sus actividades distintivas, así como la realización de informes particulares en la medida que sea considerado pertinente para el mejor ejercicio de su acción.

Los resultados de la encuesta efectuada, más allá de ciertas diferencias, nos dejan también aspectos centrales que con asiduidad forman parte de las defensorías universitarias españolas. Destacadamente, los que indicaré a continuación:

- La titularidad de la Defensoría está previsto recaiga sobre todo en Profesores y Personal de Administración y Servicios aunque también puede recaer sobre Estudiantes e incluso personalidades de prestigio ajenas a la comunidad universitaria. En la actualidad, Girona hace uso de esta última figura y, en la Universidad de León, por ejemplo, de los nueve defensores que han ejercido el cargo durante estos años, dos fueron estudiantes.

- La persona titular está particularmente protegida durante su mandato y, para garantizar su independencia y el correcto cumplimiento de sus funciones, rara vez se prevé que su candidatura dependa de la voluntad del rector, aunque sí del Claustro o de un número de avales dentro de la comunidad universitaria; es elegida a menudo por una mayoría cualificada de claustrales; puede ser removida por causas graves, tasadas por los reglamentos; no ostenta cargos representativos dentro de la Universidad (en ocasiones, tampoco fuera); suele contar con un presupuesto elaborado de manera au- 
tónoma; está habilitada para asistir a reuniones de órganos y comisiones de carácter ejecutivo.

- Por lo general (en las universidades públicas), formalmente se asimila el cargo a vicerrector y también lo está su retribución y su descarga docente. Más plural es, en cambio, su posición en la Universidad privada. También varía la duración del mandato, predominando la previsión de entre tres y cuatro años renovables o bien, cinco años por una sola vez.

- Las defensorías tienden a garantizar la discreción sobre las quejas habilitando un registro específico distinto del general; colaboran en los procedimientos de prevención de acoso, organizan jornadas y cursos relacionados con los derechos de estudiantes, trabajadores y profesores, así como con la calidad del sistema universitario; cooperan en acciones y órganos de carácter social, particularmente, interactúan con los representantes de la Comunidad Universitaria y están presentes en las unidades de igualdad. Un importante porcentaje de defensorías proponen, además de recomendaciones, textos articulados para su aprobación por los órganos de gobierno de la Universidad. 